\title{
Self-Esteem Anak Sekolah Dasar Dengan Disleksia
}

\author{
Arina Isyalhana, Farida Kurniawati \\ Universitas Indonesia, Indonesia \\ Email: isyalhana92@gmail.com, farida1@ui.ac.id
}

\begin{abstract}
Dyslexia is the most common specific learning disorder. Around 5\% - 15\% of elementary school students have dyslexia (APA, 2013). Children with dyslexia might appear different at school and tend to get lower academic scores in comparison with their peers. Hence, this may increase the possibility for the children with dyslexia to have low self-esteem (Mash \& Wolfe, 2016) because their peers' opinions about them play an important role in affecting their self-esteem (Veenstra et al., 2007, dalam Taylor, Hume, \& Welsh, 2010). The aim of this study is to give a representation about the effect of dyslexia to the self-esteem of elementary school students with the expectance to increase the awareness to detect and give early intervention to dyslexic children. The research method is literature review using articles obtained online from several databases. There were 5 selected research articles with the criteria of the participants in the study aged between $6-12$ years old, and the used the instruments to measure specific learning disorder and also self-esteem. The result of this literature review shows that dyslexia can affect the self-esteem of elementary school students.
\end{abstract}

Keywords: Dyslexia, learning disorder, self-esteem, elementary school students.

\begin{abstract}
Abstrak
Disleksia adalah gangguan belajar spesifik yang paling banyak terjadi. Sebanyak $5 \%-15 \%$ anak sekolah menyandang disleksia (APA, 2013). Anak dengan disleksia akan terlihat berbeda di sekolah dan nilai akademisnya cenderung lebih rendah dibandingkan teman sebayanya, sehingga meningkatkan kemungkinan untuk memiliki self-esteem yang rendah (Mash \& Wolfe, 2016). Hal ini dimungkinkan mengingat teman sebaya memainkan peranan yang penting bagi perkembangan anak di usia sekolah dasar (Taylor, Hume, \& Welsh, 2010). Tujuan dari penelitian ini adalah untuk mengetahui gambaran mengenai pengaruh disleksia pada self-esteem anak usia sekolah dasar. Metode penelitian ini adalah kajian literatur dengan menggunakan artikel yang diterbitkan dalam rentang 10 tahun terakhir. Artikel tersebut diperoleh secara daring dari beberapa database. Ada 5 artikel riset kuantitatif yang terpilih dengan kriteria partisipan dalam penelitian tersebut berusia antara $6-12$ tahun, serta menggunakan instrumen untuk mengukur gangguan belajar dan juga self-esteem pada anak. Hasil dari kajian literatur ini menunjukkan bahwa self-esteem pada anak usia sekolah dasar dapat dipengaruhi oleh disleksia yang dimilikinya.
\end{abstract}

Kata kunci: Disleksia, gangguan belajar, self-esteem, anak sekolah dasar

\section{Pendahuluan}

Disleksia adalah gangguan belajar spesifik dalam kemampuan membaca, ditandai dengan kesulitan untuk membedakan bunyi dari huruf, kesulitan dalam kelancaran membaca, dan memahami maksud dari bacaan (Mash \& Wolfe, 2016). Disleksia salah satu gangguan belajar yang paling sering ditemui. Prevalensi disleksia adalah 5\% - 15\% pada anak usia sekolah (APA, 2013). Anak dengan disleksia memiliki kesulitan untuk memproses kata sehingga terhambat untuk membaca. Disleksia bisa juga disertai dengan gangguan belajar lain, seperti diskalkulia dan disgrafia.

Anak dengan disleksia memiliki tingkat kecerdasan yang normal dan bisa belajar namun harus melalui proses yang lebih kompleks dibandingkan dengan anak tanpa disleksia (Mash \& Wolfe, 2016). Gangguan belajar spesifik ini biasanya terdeteksi pada usia anak sekolah, bisa terlihat dari pencapaian akademisnya. Namun keterbatasan informasi untuk guru dan orang tua mengenai disleksia bisa menyebabkan kurangnya kesadaran atas gangguan belajar ini. Oleh karena itu, anak yang memiliki kesulitan di bidang akademis bisa dilabeli sebagai anak yang slow learner, malas, atau bahkan bodoh oleh teman-temannya (Sethi, 2014).

Gangguan belajar seperti disleksia adalah gangguan yang tidak terlihat secara fisik, maka dari itu anak dengan disleksia merasa frustrasi untuk meyakinkan orang lain bahwa kesulitan belajar yang dialami benar terjadi. Orang tua yang memiliki anak dengan disleksia juga mendapatkan kesulitan untuk menjelaskan pada guru dan juga orang tua lain bahwa kondisi anaknya tidak mengada-ada dan tidak hanya meminta keistimewaan akademis (Handriana, 2016).

Disleksia tidak hanya memengaruhi pencapaian akademis, namun juga kegiatan dalam kehidupan sehari-hari. Anak bisa mengalami kesulitan dalam mengisi formulir, mengikuti petunjuk jalan, atau pun mengikuti instruksi sederhana dari orangtua. Hal yang sederhana bisa menjadi hal yang 
membingungkan dan membuat frustrasi sehingga dapat mempengaruhi self-esteem anak dengan disleksia (Mash \& Wolfe, 2016).

Tanda dari disleksia bisa terlihat sejak usia dini, namun baru terkonfirmasi pada saat anak bersekolah di sekolah dasar dan intervensi tidak selalu dilakukan (Pesova, Sivevska, \& Runceva, 2014). Disleksia biasanya baru terdeteksi apabila hasil tes dalam kemampuan membaca anak jauh dibawah standar yang diharapkan untuk usia dan tingkat kecerdasan anak. Apabila pendampingan belajar pada anak disleksia terlambat dilakukan, gangguan belajar bisa menjadi lebih sulit untuk ditangani dan berpengaruh pada self-esteem anak yang dapat menyebabkan performa yang buruk di sekolah, depresi, dan juga perilaku sosial yang negatif (Zare \& Riasati, 2012, dalam Filippello et al., 2019).

Anak biasanya mulai mengikuti pendidikan formal di sekolah dasar dalam rentang usia 6 tahun hingga 12 tahun. Pada usia ini, anak diharapkan untuk bisa menguasai kemampuan untuk membaca, menulis, dan berhitung (Santrock, 2010). Menurut teori perkembangan dari Erikson (dalam Santrock, 2010), anak pada usia sekolah dasar sedang mengalami tahap perkembangan keempat, yaitu industry versus inferiority. Pencapaian dalam bidang akademis menjadi hal yang penting bagi mereka. Oleh karena itu, hasil yang kurang baik dan di bawah rata-rata kelas akan membuat mereka merasa tertinggal dibandingkan dengan teman-teman sebaya.

Pada anak usia sekolah, pandangan dari teman adalah hal yang penting (Veenstra et al., 2007, dalam Taylor, Hume, \& Welsh, 2010). Anak yang berbeda biasanya akan mendapatkan perlakuan kurang baik atau bahkan di-bully oleh teman sebayanya. Anak dengan disleksia sering dianggap berbeda di antara teman sebayanya karena mengalami kesulitan untuk memahami non-verbal cues dari lawan bicaranya (Dewi, 2019). Mereka terlihat berbeda karena mereka tidak peka terhadap norma dan aturan sosial yang berlaku di masyarakat. Hal ini menyebabkan sekolah dianggap sebagai pengalaman yang negatif karena harus menghadapi penilaian dari orang-orang di sekitarnya dan juga tuntutan akan pencapaian akademis yang sangat menantang untuk anak dengan disleksia (Bonifacci, Storti, Tobia, \& Suardi, 2015). Hal ini dapat memberikan pengaruh negatif bagi self-esteem anak.

Self-esteem adalah penilaian seseorang akan nilai dari dirinya yang muncul dari proses perbandingan dan negosiasi antara persepsi diri dan diri yang ideal (Alesi, Rappo, \& Pepi, 2012). Self-esteem juga berhubungan dengan rasa aman dan stabil akan hubungan dengan teman di sekolah (Filippello et al., 2019). Self-esteem dan peer attachment yang positif adalah faktor penting yang mempengaruhi produktivitas dan kreativitas. Sebaliknya, apabila anak memiliki self-esteem yang negatif dan hubungan dengan peer yang buruk, dapat menyebabkan depresi, perilaku yang berisiko, dan helplessness (Park \& Park, 2015, dalam Filippello, et al., 2019). Oleh karena itu, self-esteem tidak hanya dipengaruhi dari dalam diri sendiri, tapi juga kualitas dari hubungan interpersonal.

Mengacu pada penjelasan di atas, kajian literasi ilmiah ini bertujuan untuk mengeksplorasi gambaran self-esteem anak usia sekolah dasar yang menyandang disleksia. Hasil dari penelitian ini diharapkan bisa menjadi dasar untuk meningkatkan kesadaran orangtua dan pihak sekolah akan pentingnya deteksi dan intervensi dini pada kesulitan belajar anak yang mungkin dapat mempengaruhi self-esteem pada anak.

\section{Metode Penelitian}

Penelitian ini menggunakan metode kajian literatur. Literatur yang digunakan adalah artikel jurnal/penelitian yang diperoleh secara daring. Analisis terhadap literatur bertujuan untuk mengetahui gambaran self-esteem pada anak usia sekolah dasar dengan disleksia. Pencarian sistematis dilakukan pada mesin pencarian elektronik, dibatasi untuk hanya menyertakan artikel jurnal berbahasa Inggris, full text, dan diterbitkan antara bulan Januari 2010 hingga Oktober 2019. Literatur yang digunakan terbentang dari sepuluh tahun terakhir untuk mengetahui isu terkini dan perkembangan mengenai isu tersebut. Menurut Menteri Pendidikan dan Kebudayaan (2018), usia minimal anak masuk sekolah dasar adalah 6 tahun. Oleh karena itu, usia anak yang dipilih adalah antara 6-12 tahun, yaitu usia anak sekolah dasar. Pencarian studi ilmiah dilakukan dengan tiga database yang bisa diakses jarak jauh, yaitu Taylor \& Francis Online, SAGE Journals, dan ScienceDirect. Kata kunci pencarian pada database Taylor \& Francis Online yakni: (a) ('dyslexia' AND 'self-esteem' AND 'primary school student') dan (b) ('dyslexia' AND 'self-esteem' AND 'elementary school student'). Dari proses pertama (a), peneliti menemukan 262 studi ilmiah sebelum seleksi lanjutan yang berkaitan dengan kata kunci. Dari proses kedua (b), peneliti menemukan 205 studi ilmiah terkait kata kunci. Selanjutnya, pencarian pada 
database SAGE Journals menggunakan kata kunci: (a) ('specific learning disorder' AND 'self-esteem' AND 'primary school student') dan (b) ('specific reading disorder' AND 'self-esteem' AND 'elementary school student'). Kata kunci yang digunakan sedikit berbeda agar hasil pencarian lebih bervariasi dan menghindari studi ilmiah yang sama dengan hasil pada database pertama. Pencarian dengan kaca kunci (a) menghasilkan 2423 artikel, dan ditemukan 1532 artikel dari proses pencarian kedua (b) sebelum dilakukan seleksi lanjutan. Di samping itu, dilakukan pencarian pada database ScienceDirect menggunakan kata kunci 'reading disability' AND 'self-esteem' AND 'primary school student'. Pencarian dengan kata kunci tersebut menghasilkan 366 studi ilmiah yang kemudian akan diseleksi lebih lanjut. Artikel dari ketiga database tersebut kemudian disaring dengan hanya memasukkan artikel yang membahas self-esteem pada anak dengan disleksia di usia yang sudah ditentukan. Proses pemilihan studi ilmiah yang akan dikaji dimulai dari memilih judul dan abstrak yang sesuai. Kemudian artikel tersebut diseleksi berdasarkan tujuan penelitian, metode, dan hasil. Tahap terakhir dari proses seleksi artikel ilmah yang akan dikaji adalah pemberian keputusan apakah studi tersebut terseleksi atau tereliminasi. Dari hasil pencarian pada database Taylor \& Francis Online total 467 studi, yang dipertimbangkan dengan mengeliminasi artikel berdasarkan judul dan abstrak adalah 6 studi, dan yang terseleksi hanya 1 studi. Proses seleksi ini mengeliminasi artikel yang berada di luar konteks pencarian. Beberapa alasan artikel dieliminasi adalah : (1) partisipan penelitian tidak berada dalam rentang usia yang ditentukan; (2) partisipan penelitian sudah berada di sekolah menengah pertama; dan (3) pengujian pada variabel lain yang tidak berkaitan. Hasil dari proses pencarian pada database ini diperlihatkan dalam diagram pada Gambar 1.

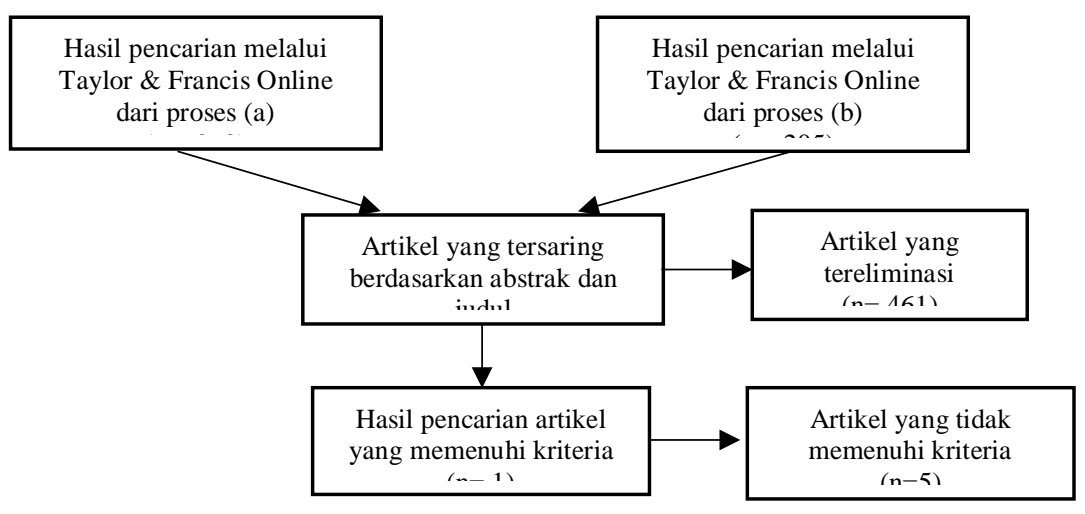

Gambar 1. Diagram pencarian studi ilmiah pada database Taylor \& Francis Online

Pada database kedua, dari total 3955 studi, terjaring 6 studi untuk dipertimbangkan dan terseleksi 2 studi yang sesuai dengan kriteria yang ditentukan. Artikel yang tidak memenuhi kriteria memiliki alasan sebagai berikut: (1) memiliki subyek penelitian yang berbeda, (2) meneliti self-esteem tidak dalam konteks sekolah, (3) usia partisipan tidak berada di rentang yang ditentukan, dan (4) fokus studi terkait dengan peer acceptance. Proses pencarian pada database SAGE Journals ditunjukkan pada Gambar 2.

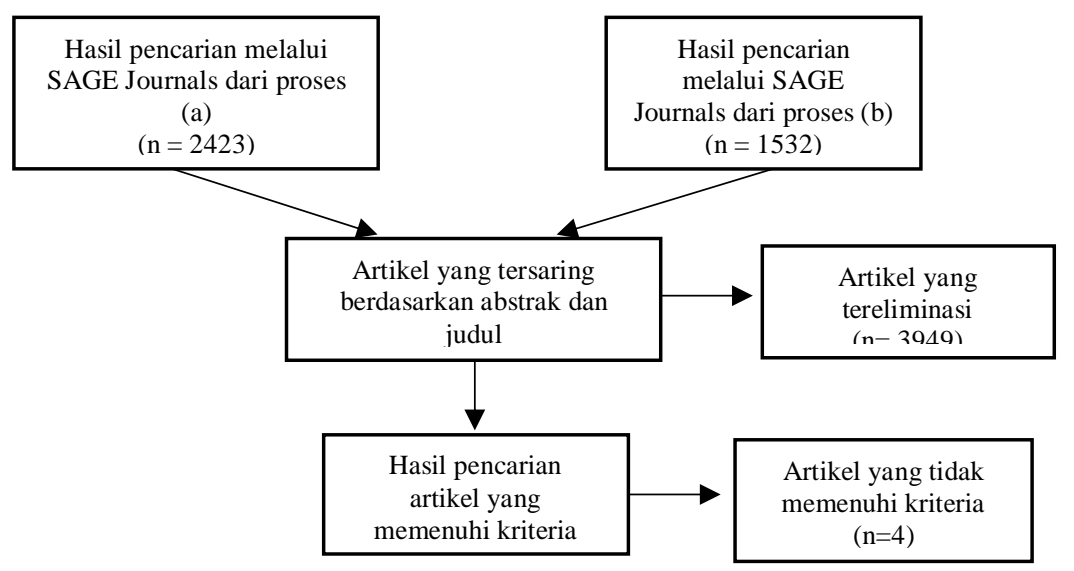

Gambar 2. Diagram pencarian studi ilmiah pada database SAGE Journals

Psyche 165 Journal Terakredetasi Sinta 5 
Dari total 366 studi yang muncul di pencarian pada database ScienceDirect, terjaring 5 studi yang berkaitan dengan kata kunci. Setelah diseleksi, ada 2 studi yang sesuai dengan kriteria yang ditentukan. Beberapa artikel yang tidak terpilih merupakan duplikasi hasil pencarian dari kedua database di atas. Alur pencarian artikel jurnal pada database ketiga diperlihatkan pada Gambar 3

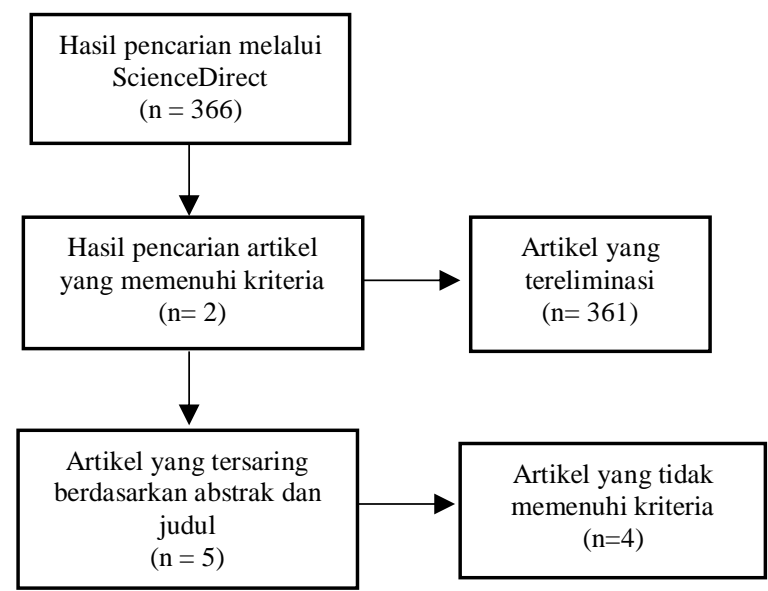

Gambar 3. Diagram pencarian studi ilmiah pada database ScienceDirect

Dari total 4788 studi dari ketiga database, tereliminasi 4783 studi dan terseleksi 5 artikel jurnal yang sesuai dengan kriteria untuk dikaji lebih lanjut mengenai gambaran self-esteem pada anak usia sekolah dasar yang menyandang disleksia.

\section{Hasil dan Pembahasan}

Studi yang terpilih berjumlah 5 dan merupakan riset kuantitatif. Rincian temuan pada kelima artikel disajikan dalam Tabel 1.

Tabel 1. Gambaran Umum Studi Terpilih

Gambaran Self-esteem pada Anak Sekolah Dasar Penyandang Disleksia

\begin{tabular}{lll}
\hline \multicolumn{1}{c}{ Studi, Negara } & \multicolumn{1}{c}{ Partisipan } & \multicolumn{1}{c}{ Metodologi } \\
\hline Chan, Chan, Cheng, & 49 anak dengan specific & Pengisian kuesioner mengenai data \\
Chow, Tsang, Lee, \& & learning disorder $(S L D)$ dan & demografi. \\
Lin (2017). Hong Kong & 32 anak tanpa $S L D$ dengan & Diagnosa SLD ditentukan dengan \\
& rentang usia 8-12 tahun & Hong Kong test of specific learning \\
& difficulties (HKT-SpLD) \\
& Self-esteem pada anak diukur \\
& dengan Kid-KIDLN (Ravens- \\
& Sieberer \& Bullinger, 2000) yang \\
& terdiri dari 24 soal; 6 domain \\
& (physical well-being, emotional \\
& well-being, self-esteem, family, \\
& friends, dan school) yang terdiri \\
& dari 4 soal per domain.
\end{tabular}

Turunen, Poskiparta, \& 6691 siswa kelas 3-5 SD dari $\quad$ Siswa mengisi kuesioner data Salmivalli (2017). Finlandia

Alesi, Rappo, \& Pepi (2012). Italia berbagai sekolah yang mewakili semua sekolah dari 5 provinsi di Finlandia
56 anak dengan rentang usia 7-9 tahun di jenjang kelas 3 sekolah dasar dan menyandang specific reading disabilities demografis.

Reading difficulty ( $R D)$ diukur dengan self-reported reading difficulty.

Rosenberg Self-esteem Scale (Rosenberg, 1965) digunakan untuk mengukur self-esteem siswa. Skala ini terdiri dari 10 pernyataan yang direspon oleh siswa dengan 5-point Likert-type scale.

Specific reading disabilities diukur dengan instrument The Reading Comprehension Test (Cornoldi \& Colpo, 2001), The Reading Decoding Test, dan Dyslexic and
Temuan Utama

Anak dengan $S L D$ memiliki selfesteem yang lebih rendah dibandingkan dengan anak tanpa $S L D$. Hal ini bisa dipengaruhi oleh kultur karena Hong Kong sangat mementingkan pencapaian akademis.

Siswa dengan self-esteem yang lebih tinggi memiliki peluang yang lebih rendah untuk terlibat dalam perilaku bullying, baik sebagai korban atau pelaku. Siswa yang memiliki $R D$ cenderung untuk terlibat dalam perilaku bullying. Oleh karena itu, siswa dengan $R D$ memiliki self-esteem yang lebih rendah daripada siswa tanpa $R D$.

Anak dengan specific reading disabilities memiliki scholastic self-esteem yang lebih rendah dibandingkan dengan anak tanpa specific reading disabilities. Hal 
Bonifacci, Storti, Tobia, $\&$ Suardi (2015). Italia

Novita (2016). Jerman
34 keluarga (ayah, ibu, dan anak). Rentang umur anak adalah 7-13 tahun.

17 anak didiagnosa menyandang $S L D$ dan 17 anak tidak memiliki $S L D$.

Partisipan penyandang $S L D$ direkrut dari klinik yang mendiagnosa dan mengintervensi learning disorder

124 anak kelas 3 atau 4 di sekolah dasar dengan rentang usia 8-11 tahun. 60 anak menyandang disleksia dan 64 anak tidak menyandang disleksia.

Partisipan dengan disleksia didiagnosa oleh psikolog.
Disorthographic Evaluation Test (Sartori, Job, \& Tressoldi, 1995). Self-esteem diukur dengan Test Multidimensionale dell'Autostima Multidimensional (TMA) atau diketahui juga sebagai Test of Selfesteem (Bracken, 1992) Data demografis diisi oleh orangtua. TMA (Bracken, 2003) digunakan untuk mengetahui self-esteem anak. Tes tersebut terdiri dari 150 pernyataan untuk mengetes 6 dimensi dari self-esteem, yaitu interpersonal, skills, emotional, school, family dan body).

Instrument yang digunakan untuk mengukur self-esteem adalah Selfesteem Test for Childern and Adolescents (Aussagen-Liste zum Selbstwertgefühl für Kinder und Jugendliche / ALS) (Schauder, 1991). ALS tidak hanya dapat membedakan hasil self-esteem umum dan pada konteks spesifik, namun juga membuat asumsi mengenai permasalahan mengenai self-esteem yang mungkin akan dihadapi anak di sekolah. ini bisa terjadi karena self-esteem memiliki kaitan yang erat dengan pencapaian akademis.

SLD mungkin berdampak pada domain yang spesifik dalam selfesteem, terutama pada aspek skolastik yang dapat meluas ke aspek interpersonal. Kesulitan dalam bidang akademis yang dihadapi di sekolah dapat memengaruhi hubungan dengan teman sekelas secara negatif. Namun, anak dengan SLD tidak menunjukkan self-esteem yang lebih rendah pada domain lainnya Secara umum, anak dengan dan tanpa disleksia memiliki selfesteem yang sama. Namun anak dengan disleksia memiliki selfesteem yang lebih rendah dalam aspek sekolah dibandingkan dengan anak yang tidak memiliki kesulitan membaca.

Dari 5 studi ilmiah yang dikaji, ada 3 studi yang meneliti mengenai domain dalam self-esteem dan menunjukkan bahwa domain dalam aspek pendidikan adalah yang paling terpengaruhi apabila anak memiliki disleksia (Alesi, Rappo, \& Pepi, 2012; Bonifacci, Storti, Tobia, \& Suardi, 2015; Novita 2016). Budaya yang dimiliki negara tempat partisipan tinggal (Chan et al., 2017) juga mempengaruhi selfesteem pada anak dengan kesulitan belajar karena ekspektasi yang tinggi dari lingkungan sekitar. Secara keseluruhan hasil dari studi ilmiah yang terpilih menyatakan bahwa anak usia sekolah dasar yang menyandang kesulitan belajar spesifik memiliki self-esteem yang rendah.

Berdasarkan hasil penelitian, terdapat beberapa temuan mengenai self-esteem pada anak disleksia. Pertama, pencapaian akademis merupakan hal yang penting dalam beberapa budaya, sehingga dapat menjadi salah satu prediktor dari self-esteem. Tingkat pencapaian yang rendah membuat anak dengan disleksia merasa inferior di dalam lingkungan akademis yang kompetitif (Chen et al., 2017). Budaya yang menjunjung tinggi nilai akademis bisa menganggap anak penyandang disleksia sebagai anak yang bodoh atau malas, tanpa mengetahui bahwa anak tersebut memiliki kesulitan belajar.

Perasaan rendah diri yang dirasakan oleh anak dengan disleksia akan mempengaruhi hubungan pertemanannya. Penelitian menyatakan bahwa anak dengan gangguan belajar cenderung untuk terlibat dalam bullying, baik sebagai korban maupun pelaku (Turunen, Poskiparta, \& Salmivalli., 2017). Perilaku ini bisa timbul sebagai hasil dari frustrasi yang disebabkan oleh berbagai kesulitan yang dihadapi di sekolah. Anak dengan disleksia tidak berbeda secara fisik dengan anak yang lain, sehingga kesulitan belajarnya seringkali dianggap tidak benar. Hal tersebut dapat menyebabkan anak merasa tidak mampu secara akademis dan sulit untuk berteman dengan teman sebaya. Oleh karena itu, kepedulian dan kepekaan terhadap anak yang terlibat dalam bullying perlu ditingkatkan sehingga dapat diintervensi sejak dini. Sistem pendukung yang memadai juga diharapkan dapat mendampingi anakanak tersebut selama masa sekolah.

\section{Kesimpulan}

Pencapaian dalam bidang akademis dan hubungan pertemanan merupakan beberapa hal yang memengaruhi self-esteem pada anak usia sekolah. Anak penyandang disleksia cenderung untuk memiliki kekurangan dalam kedua hal tersebut sehingga biasanya memiliki self-esteem yang rendah. Tiga dari lima penelitian yang dikaji menggunakan alat ukur yang mengukur aspek self-esteem yang spesifik. Hasil dari penelitian tersebut menyatakan bahwa anak dengan disleksia memiliki self-esteem 
yang rendah dalam konteks sekolah, yaitu aspek skolastik dan interpersonal. Penelitian ini menyoroti peran penting sekolah yang dapat memengaruhi self-esteem pada anak. Kesulitan dan tantangan yang paling besar dihadapi oleh anak dengan gangguan belajar adalah ketika mulai masuk sekolah. Oleh karena itu, pentingnya kemampuan guru dan pihak sekolah untuk mendeteksi dini gangguan belajar agar aspek yang dapat memengaruhi self-esteem bisa diminimalisir. Limitasi dari penelitian ini adalah keterbatasan artikel mengenai disleksia pada anak usia sekolah. Mayoritas dari studi ilmiah meneliti mengenai gangguan belajar secara keseluruhan dengan mengikut sertakan gangguan belajar lainnya, seperti disgrafia dan diskalkulia. Kemudian banyak artikel yang meneliti mengenai disleksia pada remaja atau dewasa, sehingga penelitian mengenai disleksia pada anak usia sekolah dasar sangat terbatas. Instrumen yang digunakan untuk mengukur self-esteem dan SLD dalam setiap penelitian berbeda-beda, sehingga hasil mungkin tidak bisa digeneralisasikan ke semua budaya.

Untuk mendeteksi disleksia, sebaiknya menggunakan alat ukur yang dirancang khusus untuk budaya tersebut agar hasilnya lebih akurat. Hal ini mengingat fonem yang dimiliki setiap bahasa berbeda-beda sehingga alat ukurnya harus menyesuaikan penggunaan bahasa pada daerah tersebut. Salah satu kendala yang dapat terjadi di Indonesia adalah negara ini terdiri dari suku dan budaya yang sangat beragam dan memiliki bahasa masing-masing, sehingga yang dapat dilakukan adalah menggunakan tes yang dikembangkan dengan menggunakan Bahasa Indonesia. Selain itu agar dapat mengetahui bagian mana dari self-esteem yang terpengaruhi oleh gangguan belajar yang disandang oleh anak sekolah dasar, penelitian dapat mempertimbangkan penggunaan Test Multidimensionale dell'Autostima Multidimensional (TMA). Berdasarkan penelitian, beberapa negara di Asia merupakan kultur yang memiliki ekspektasi pencapaian akademis yang tinggi, sehingga mengukur aspek-aspek yang berbeda dari self-esteem dapat memberikan gambaran yang lebih mendalam mengenai pengaruh disleksia terhadap self-esteem anak. Untuk melakukan penelitian di Indonesia, kedua instrumen tersebut dapat digunakan untuk mengetahui gambaran self-esteem pada anak penyandang disleksia. Penelitian ini diharapkan dapat menjadi dasar bagi pembuat kebijakan untuk meningkatkan kesadaran mengenai gangguan belajar. Guru di harapkan dapat diedukasi untuk memahami gangguan belajar dan diberikan pelatihan agar dapat mengajar anak berkebutuhan khusus dalam belajar.

\section{Daftar Rujukan}

Alesi, M., Rappo, G., \& Pepi, A. (2012). Self-esteem at school and self-handicapping in childhood: Comparison of groups with learning disabilities. Psychological Reports: Disability \& Trauma, 111(3), 952-962. doi: 10.2466/15.10.PR0.111.6.952-962

American Psychiatric Association. (2013). Diagnostic and statistical manual of mental disorder DSM-V (5th ed.). Washington DC: Author.

Antonelli, L., Bilocca, S., Borg, D., Borg, S., Boxall, M., Briffa, L., Debono, C., Falzon, R., Farrugia, V., Gatt, L., Formosa, M., Mifsud, D., Mizzi, K., Scurfield, L., Scurlield, M., \& Vella, L. G. (2014). Drama, performance ethnograpgy, and self-esteem: Listening to youngsters with dyslexia and their parents. SAGE Open, 1-15. doi: 10.1177/2158244014534696

Bonifacci, P., Storti, M., Tobia, V., \& Suardi, A. (2015). Specific learning disorder: A look inside children's and parents' psychological well-being and relationships. Journal of Learning Disabilities, 49(5), 532-545. doi: 10.1177/0022219414566681

Chan, Y., Chan, Y. Y., Cheng, S. L., Chow, M. Y., Tsang, Y. W., Lee, C., \& Lin, C. Y. (2017). Investigating quality of life and self-stigma in Hong Kong children with specific learning disabilities. Research in Developmental Disabilities, 68, 131-139. doi: 10.1016/j.learninstruc.2017.05.007

Dewi, K. (2019). Apa itu Disleksia? Retrieved from Asosiasi Disleksia Indonesia: https://www.asosiasidisleksiaindonesia.com/article.php

Filippello, P., Buzzai, C., Messina, G., Mafodda, A. V., \& Sorrenti, L. (2019). School refusal in students with low academic performances and specific learning disorder. The role of self-esteem and perceived parental psychological control. International Journal of Disability, Development, and Education, 1-16. doi: $10.1080 / 1034912$ X.2019.1626006

Handriana, E. (2016, April 26). Anak disleksia hanya kehilangan huruf, bukan masa depan. Retrieved from Rappler: https://www.rappler.com/indonesia/130815-anak-disleksia-kehilangan-huruf-bukan-masadepan

Jap, B.A.J., Borleffs, E., \& Maassen, B.A.M. (2017). Towards identifying dislexia in Standard Indonesian: The development of a reading assessment battery. Reading and Writing, 30, 1729-1751. doi:

10.1007/s11145-017-9748-y 
Mash, E., \& Wolfe, D. (2016). Abnormal child psychology ( $6^{\text {th }}$ ed.). Boston: Cengage Learning.

Novita, S. (2016). Secondary symptoms of dyslexia: A comparison of self-esteem and anxiety profiles of children with and without dyslexia. European Journal of Special Needs Education, 31(2), 279-288. doi: 10.1080/08856257.2015.1125694

Menteri Pendidikan dan Kebudayaan Republik Indonesia. (2018). Peraturan menteri pendidikan dan kebudayaan Republik Indonesia nomor 14 tahun 2018 tentang penerimaan peserta didik baru pada taman kanak-kanak, sekolah dasar, sekolah menengah atas, sekolah menengah kejuruan, atau bentuk lain yang sederajat. Diakses dari https://jdih.kemdikbud.go.id/arsip/Permendikbud_Tahun2018 Nomor14.pdf

Pesova, B., Sivevska, D., \& Runceva, J. (2014). Early intervention and prevention of students with specific learning disabilities. Procedia - Social and Behavioral Sciences, 701-708. doi: 10.1016/j.sbspro.2014.08.259

Santrock, J. W. (2010). Child development (13 ${ }^{\text {th }}$ ed.). New York: McGraw-Hill.

Sethi, Z. (2014). Learning disabilities in school-going children. New Horizons, 8(2), 121-136.

Taylor, L. M., Hume, I. R., \& Welsh, N. (2010). Labelling and self-esteem: The impact of using specific vs generic labels. Educational Psychology, 30(2), 191-202. doi: 10.1080/01443410903494478

Turunen, T., Poskiparta, E., \& Salmivalli, C. (2017). Are reading difficulties associated with bullying involvement?. Learning and Instruction, 52, 130-138. doi: 10.1016/j.learninstruc.2017.05.007 